\title{
Understanding Instructor Nonverbal Immediacy, Verbal Immediacy, and Student Motivation at a Small Liberal Arts University
}

\begin{abstract}
Stephen A. Furlich
Abstract: Instructor communication behaviors and student motivation to learn relationships were studied at a small liberal arts university. Specifically, relationships between instructor nonverbal immediacy, verbal immediacy behaviors and student motivation to learn were measured. Only instructor verbal immediacy behaviors had a significant linear regression relationship result with student motivation to learn. These results from a small liberal arts university are discussed in reference to previous research that measured these variables primarily at research universities. The results and implications are addressed for instructors and administrators.
\end{abstract}

Keywords: small liberal arts university, nonverbal immediacy, verbal immediacy, student motivation.

\section{Introduction}

Higher education institutions play a large role in our society. It is not possible for one type of institution to fulfill all of society's needs. Therefore, different types of higher education institutions are needed to meet the varying demands of our society. One such higher education institution is a small liberal arts university. Understanding instructional behaviors at small liberal arts universities can help improve that type of institution.

One area of instructional behaviors that small liberal arts universities can address to improve their instruction is instructor immediacy behaviors. Instructor immediacy behaviors are those that communicate approachability (Mehrabian, 1971). People tend to communicate with and become close to people they like and avoid communicating with people they dislike (Mehrabian, 1971; Sidelinger, 2010; Witt \& Kerssen-Griep, 2011). Previous immediacy research has shown positive outcomes within the classroom but have been conducted almost entirely at research universities (Elliot \& Knight, 2005; Ellis, 2004). The purpose of this study is to better understand associations of instructor immediacy behaviors, nonverbal and verbal, and student motivation to learn at a small liberal arts university.

\section{Small Liberal Arts University}

According to the Carnegie Foundation for the Advancement of Teaching (2010) a Small Liberal Arts University is classified as an institution consisting of smaller programs and awards at least 50 Master's degrees per year. Students and instructors at a small liberal arts university can differ from those at other types of institutions (Dickson, 1999; Modern Language Association, 2006; 
Ovington, Diamantes, Roby, \& Ryan, 2003; Sorcinelli, 2002). Pascarella, Wang, Trolian, and Blaich (2013) state that small liberal arts universities place a primary emphasis on teaching. This is often evident when reviewing faculty promotion requirements for the institutions (Donelan, 2004; Ovington, Diamantes, Roby, \& Ryan, 2003; Sorcinelli, 2002). Students are often aware of this instructional focus and choose an institution to attend based upon this factor. This can influence student perceptions of instructor immediacy behaviors (Dickson, 1999; Modern Language Association, 2006; Ovington, Diamantes, Roby, \& Ryan, 2003; Sorcinelli, 2002).

The primary focus of teaching by small liberal arts university instructors places a heavy emphasis on communication interactions with students. Usually, class sizes are smaller at small liberal arts universities compared to other institutional types (Pascarella, Wang, Trolian, \& Blaich, 2013). These smaller classes at small liberal arts universities allow more opportunities for students to engage with their instructors on a personal level. This can occur both inside and outside the classroom, such as in their office.

\section{Instructor Immediacy and Student Motivation to Learn}

Student engagement with instructors on a personal level can come in the form of instructor immediacy behaviors. Positive classroom outcomes can occur from instructors displaying immediacy behaviors (Houser, 2005; Pogue, \& Ahyun, 2007; Sidelinger, 2010; Velez, \& Cano, 2008; Witt \& Kerssen-Griep, 2011; Zhang, Oetzel, Gao, Wilcox, \& Takai, 2007). Previous research indicates that instructor immediacy behaviors, verbal and nonverbal, are positively related to student motivation to learn (Anderman, 2004; Elliot \& Knight, 2005; Frymier, 1994; Harrison, 2011; Pogue, \& Ahyun, 2007; Sidelinger, 2010; Witt, Wheeless, \& Allen, 2004). Student motivation is important to understand because it plays an important role with student learning (Frymier, \& Houser, 2000; Paas, Tuovinen, Merrienboer, \& Darabi, 2005; Witt, Wheeless, \& Allen, 2004). Studies suggest that when students are motivated to learn they also tend to perform better in their classes (Lebedina-Manzoni, 2004; Sidelinger, 2010).

\section{Verbal Immediacy}

When applied to a teaching/learning environment verbal immediacy behaviors are verbal messages that convey the "use of pro-social as opposed to antisocial messages to alter student behavior" (Gorham, 1988, p. 41). Verbal immediacy behaviors include using personal examples, humor, engaging in conversations with students before, after, or outside of class, encouraging students to talk, referring to the class as "we," or "our," asking for students' input, teachers' self-disclosure, addressing students by name, praising students' work, allowing students to address instructors by their first name, and being available for students outside of class if they have any questions (Gorham, 1988).

\section{Nonverbal Immediacy}

Examples of nonverbal immediacy behaviors include making eye-contact, using physical gestures, having a relaxed body position, directing body position toward students, smiling, using vocal expressiveness, movement, and proximity (Andersen, 1979). Instructors displaying nonverbal immediacy behaviors can lead to beneficial outcomes (Comadena, Hunt, \& Simonds, 2007; Pogue, \& Ahyun, 2007; Witt \& Kerssen-Griep, 2011). 
Instructors displaying immediacy behaviors often have students with higher levels of motivation (Pogue, \& Ahyun, 2007; Seifert, 2004). Ellis (2004) found when instructors display behaviors similar to immediacy students' motivation to learn was likely to increase. These behaviors were a set of instructor behaviors that were used to explain a task, while another set of behaviors increased the interpersonal relationship between the instructor and student. The communication behaviors addressing a task such as covering class material included taking time to answer student questions fully. Instructors' behaviors that increased interpersonal relations with students included answering student questions in a polite manner. Ellis' study illustrates the relation between instructor immediacy behaviors and student motivation to learn at research universities. Previous immediacy research has neglected to address those behaviors within small liberal arts universities.

Out-of-class communication often in the form of conversations with students is one immediacy approach that instructors can use with students (Jaasma \& Koper, 1999). Dobransky and Frymier (2004) found an increase in interpersonal relationships between instructors and students when out-of-class communication occurred between them. More specifically, they found that the areas of trust, shared control, and intimacy, which are factors of an interpersonal relationship, increased. The findings from this study are important because students who perceived more trust, shared control, and intimacy with their instructor were also found to achieve more learning than those students who did not. Small liberal arts university students may have more opportunities to communicate with their instructors outside of class than other institutions because instructors usually have fewer students per class which enables them to become more familiar with each student (U.S. News \& World Reports, 2015). Furthermore, it is impractical to expect instructors with larger class sizes at larger institutions to have an opportunity to talk with the majority of their students outside of class. As a result, small liberal arts university students may consider it normal to have the opportunity to communicate with their instructors outside of the classroom.

\section{Rationale and Hypothesis}

Those students who are more motivated tend to measure higher levels of learning in a class (Allen, Witt, \& Wheeless, 2006). Researchers have some certainty that student motivation is likely to increase when instructors display immediacy behaviors at research universities (Pogue, \& Ahyun, 2007; Witt, Wheeless, \& Allen, 2004). However, prior research has not addressed instructor immediacy behaviors and student motivation to learn at small liberal arts universities.

Small liberal arts universities differ from those institutions from which previous immediacy research has been conducted. Small liberal arts universities are likely to have much smaller class sizes compared to institutions at which prior immediacy research has been conducted. The class size difference can create a different instructional context and interaction between an instructor and their students. It is unrealistic to expect an instructor to learn every student's name and have conversations with each student in large lecture classes. It should not be taken for granted that instructors' use of immediacy behaviors will have the same outcomes in all types of higher education institutions until different types of higher education institutions measure instructor immediacy behaviors and student motivation to learn associations and confirm this inference. This lack of research about small liberal arts universities leaves a void of research for a major portion of undergraduate students and institutions. 


\section{Hypothesis}

Hypothesis 1i: Instructor verbal immediacy behaviors are positively associated with student motivation to learn at a small liberal arts university.

Hypothesis 1ii: Instructor nonverbal immediacy behaviors are positively associated with student motivation to learn at a small liberal arts university.

\section{Methods}

\section{Procedures}

This study was conducted at a small liberal arts university located in the Midwest. A total of 4 different class sections of introductory Communication Studies classes from during weeks 6-8 of the same semester were used for this study. This study used a convenience sample. The researcher was not the instructor for any of these sections. The classes were taught by instructors the researcher knew professionally. The researcher contacted instructors teaching at the small liberal arts university and asked permission to collect data from some of their classes. Students in their classes were asked to participate in the study by filling out paper measurements of the variables of interest for this study. The instructor was not present in the room when the instruments were distributed and completed. Students in each section were asked to evaluate their instructor's verbal immediacy and nonverbal immediacy behaviors and their own motivation for that class.

Obtaining participation from students to evaluate communication behaviors concerning the class from which participation was requested has been used by previous researchers (Johnson, 2013). This was done because asking students to measure other classes they have can range from different subject areas, large lectures, small labs, different number of credit hours, etc. Furthermore, some students may only take one class during a semester. Institutional Review Board approval was received and students were asked to voluntarily fill out a pencil and paper survey packet measuring their perceptions of their instructor's verbal immediacy, nonverbal immediacy behaviors, referring to the instructor of the class that they received the survey packet and their own student motivation for that class.

\section{Participants}

There were a total of 77 undergraduate student participants enrolled in introductory Communication Studies classes in a small liberal arts university in the Midwestern region of the United States. The demographics of the participants included $52(67 \%)$ of the participants were female, 25 (32\%) male, 67 (87\%) Caucasian, 1 (1\%) African American, 0 (0\%) Hispanic, 4 (5\%) Asian-American, 5 (7\%) other. The participants had a mean age of 22 and a variety of different majors.

\section{Instrumentation}

Three instruments were used to measure the relationships among the variables for this study. The measurement instruments proved to be reliable based upon Chronbach's alpha reliability coefficients that were found in this study and in previous studies. The measurement instruments 
were not altered from their original form. The researcher in this study did add demographic items for a better understanding of the participants in this study.

Motivation to Learn. The motivation to learn measurement instrument developed by Christophel (1990) is intended to measure how motivated a student is to learn in a particular class. The instrument measured how motivated each student was for the class that they were asked to participate in the study. The measurement instrument consists of a series of bipolar words with each set separated by a semantic differential scale of 1 to 7 . The student circles the number closest to the word that best represents his or her motivation toward the class. Items 1, 2, 3, 6, 10, 11 are reverse scored. This study achieved acceptable reliability for student motivation to learn with a Cronbach's alpha level of 0.92. Construct validity was also found for this measurement instrument stemming from previous research (Rubin, Palmgreen, \& Sypher, 1994).

Verbal Immediacy. The verbal immediacy measurement instrument is intended to measure student perceptions of their instructor's verbal immediacy behaviors. The instrument measured each student's perception of their instructor's use of verbal immediacy behaviors for the class that they were asked to participate in the study. The verbal immediacy measurement instrument has 17 items. Each item presents a particular example of an instructor verbal immediacy behavior and students are asked to indicate how often their instructor displays this behavior on a scale from 0-4 ( $0=$ never, $1=$ rarely, $2=$ occasionally, $3=$ often, and $4=$ very often $)$. Item 11 is non-immediate and is reversed scored when summing. The verbal immediacy measurement instrument was developed by Gorham (1988), and has proven to be reliable (Christophel, 1990; Fang-Yi, \& Wang, 2010; Gorham \& Zakahi, 1990). A Cronbach's alpha reliability analysis was performed for the verbal immediacy measurement instrument in the present study and achieved acceptable reliability for verbal immediacy with a result of 0.82 . The instrument has been shown by previous scholars to have construct validity (Rubin, Palmgreen, \& Sypher, 1994).

Nonverbal Immediacy. The nonverbal immediacy measurement instrument is intended to measure student perceptions of their instructor's nonverbal immediacy behaviors. The instrument measured each student's perception of their instructor's use of nonverbal immediacy behaviors for the class that they were asked to participate in the study. The nonverbal immediacy measurement instrument has 14 items. Each item presents a particular example of an instructor nonverbal immediacy behavior and students are asked to indicate how often their instructor displays this behavior on a scale from $0-4(0=$ never, $1=$ rarely, $2=$ occasionally, $3=$ often, and $4=$ very often $)$. Items 1, 3, 6, 9, 10, and 11 are non-immediate and are reversed scored when summing. The nonverbal immediacy measurement instrument was developed by Richmond, Gorham, and McCroskey (1987), and has proven to be reliable. A Cronbach's alpha reliability analysis was performed for the nonverbal immediacy measurement instrument in the present study and achieved acceptable reliability for nonverbal immediacy with a result of 0.78 . The instrument has been shown by previous scholars to have construct validity (Rubin, Palmgreen, \& Sypher, 1994).

\section{Data Analysis}

The data analyses were performed to determine whether statistically significant correlational relationships existed between the independent variables of instructors' use of immediacy behaviors, verbal and nonverbal, and the dependent variable of students' motivation to learn. The 
analyses were performed by the researcher entering the sum scores of each participant for each measurement instrument separately. The sum scores of each participant were then calculated for the mean score of each participant for each measurement instrument. The summation and mean calculation were all carried out using the Statistical Package for the Social Sciences (SPSS). The first analysis attempted to answer the first part of the hypothesis for all of the participants by addressing a possible relationship between instructor verbal immediacy behaviors and student motivation to learn at a small liberal arts university through the use of a linear regression. A second independent linear regression was performed for all participants to investigate the second part of the hypothesis addressing a possible relationship between instructor nonverbal immediacy behaviors and student motivation to learn (Tabachnick \& Fidell, 2001).

\section{Results}

Hypothesis 1i: The possible correlation between instructor verbal immediacy behaviors with student motivation to learn was explored. One linear regression model was performed for instructor verbal immediacy and student motivation to learn. Instructor verbal immediacy behaviors significantly predicted student motivation $(\beta=.465, \mathrm{p}=.048)$ and explained $5 \%$ of the variance for student motivation $\left(\mathrm{R}^{2}=.053, \mathrm{~F}(1,76)=4.034, \mathrm{p}=.048\right)$.

Hypothesis 1ii: The possible correlation between instructor nonverbal immediacy behaviors with student motivation to learn was explored. When the data were analyzed independently in a linear regression the results were different from the instructor verbal immediacy and student motivation correlational result. Instructor nonverbal immediacy behaviors were not significantly related to student motivation to learn. Instructors' nonverbal immediacy behaviors did not have a relationship with students' motivation $(\beta=.384, \mathrm{p}=.304)$ and did not explain variance for student motivation $\left(\mathrm{R}^{2}=.015, \mathrm{~F}(1,76)=1.070, \mathrm{p}=.304\right)$.

\section{Discussion}

This study was intended to investigate relationships between instructor verbal immediacy and instructor nonverbal immediacy behaviors and student motivation to learn from a small liberal arts university. The results indicated a positive relationship between instructor verbal immediacy behaviors and student motivation to learn. No relationship was found for instructor nonverbal immediacy and student motivation to learn. Future researchers should investigate the relationships between instructor verbal immediacy and instructor nonverbal immediacy behaviors and student motivation to learn at different instructional contexts, such as those classified into different categories by the Carnegie Foundation for the Advancement of Teaching (2010).

Instructor verbal immediacy behaviors were found to account for $5 \%$ of the variance for student motivation to learn. This finding agrees with previous studies that found a positive relationship between instructor verbal immediacy behaviors and student motivation to learn which were primarily conducted at research universities, but the correlation found in this study is well below the average correlational strength found in previous research (Christensen \& Menzel, 1998; Christophel \& Gorham, 1995; Elliot \& Knight, 2005; Ellis, 2004; Frymier, 1994; Glynn, Aultman, \& Owens, 2005; Jaasma \& Koper, 1999; Seifert, 2004; Sidelinger, 2010). The evidence is exceptionally strong supporting relationships between instructor verbal immediacy behaviors and student motivation whether from previous research conducted at research universities or to a lesser extent the findings from this study collected at a small liberal arts university. Small liberal arts 
university instructors should be encouraged to display verbal immediacy behaviors by using personal examples, humor, engaging in conversations with students before, after, or outside of class, encouraging students to talk, referring to the class as "we," or "our," asking for students' input, teachers' self-disclosure, addressing students by name, praising students' work, allowing students to address instructors by their first name, and being available for students outside of class if they have any questions (Gorham, 1988).

Small liberal arts universities have teaching as the primary focus. The smaller class sizes at small liberal arts universities allow more opportunities for their faculty to display verbal immediacy behaviors with their students compared with larger class sizes at research universities (Pascarella, Wang, Trolian, \& Blaich, 2013). Small liberal arts university instructors should take advantage of their small class sizes as accommodative for displaying verbal immediacy behaviors. This study found a weaker correlation between instructor verbal immediacy behaviors and student motivation to learn than previous researchers. Therefore, instructors at small liberal arts universities with ample opportunities to display verbal immediacy behaviors in their classes should take advantage of these circumstances to display a lot of verbal immediacy behaviors to achieve higher levels of motivation with their students.

The small liberal arts university data in this study indicated no significant relationship between instructor nonverbal immediacy behaviors and student motivation to learn. This finding differs from earlier research studies finding positive relationships between these variables exclusively conducted at research universities (Pogue, \& Ahyun, 2007; Witt, Wheeless, \& Allen, 2004). This data is important because a large number of undergraduate students are enrolled in small liberal arts universities (Mayhew, 2012) and their motivation is important to understand.

It is widely accepted by instructors throughout academy who are familiar with nonverbal immediacy research that nonverbal immediacy behaviors are correlated with students' motivation to learn. Small liberal arts university instructors may then assume that these relations are intact regardless of institutional type because there is not ample previous research to suggest otherwise. It can become problematic for small liberal arts university instructors when their nonverbal immediacy behaviors that they display in class do not have the positive motivational impact with their students that they had anticipated based upon research they previously read. Small liberal arts university instructors should understand that contextual influences specific to small liberal arts universities may be at work.

The small liberal arts university from this study seems to have characteristics that differ from research universities (Donelan, 2004; Ovington, Diamantes, Roby, \& Ryan, 2003; U.S. Department of Education, 2011). For example, the small liberal arts university in this study had class sizes averaging about twenty students. Research universities average over thirty students per class (U.S. Department of Education, 2011). A student who attends a small liberal arts university class might expect more personal instruction displayed through nonverbal immediacy behaviors due to the small class size. For example, it is easier for an instructor to have eye-contact with students, stand in closer proximity, and shake hands with students in a class of twenty compared to a class of over thirty. In a class over thirty, an instructor does not have the time to display these nonverbal immediacy behaviors as much and with as many students. Communication behaviors that are not expected are noticed more than normative behaviors (Proulx \& Heine, 2008). Therefore, the display of the same instructor nonverbal immediacy behaviors in small liberal arts university classes may attract less attention than at institutions with larger classes because the small class environment can create an expectation for nonverbal immediacy behaviors to be displayed. In other words, instructor nonverbal immediacy behaviors at small liberal arts universities may be 
perceived as the norm and have less relation with student motivation to learn compared with institutions having larger classes in which nonverbal immediacy behaviors are not expected.

\section{Implications for Practice}

Instructors can always learn more ways to motivate their students (Lapka, 2012; Wiesman, 2012). Small liberal arts universities should strive to better understand instructor immediacy behaviors as related to their students' motivation to learn. Small liberal arts universities may need to find more innovative ways to display instructor immediacy behaviors because the results from this study indicate that displaying the same immediacy behaviors as those found in previous research will not result with the same outcomes of student motivation to learn.

One approach for small liberal arts university instructors to still build rapport with students through immediacy behaviors is using technology. Most instructors have probably observed the increase in use of technology by students to communicate with other people. Perhaps small liberal arts university instructors teaching face to face classes can use immediacy behaviors through technology such as Blackboard or ECollege to communicate with students. Students at small liberal arts universities might not expect their face to face classroom instructors to use technology to communicate with them using immediacy behaviors because it is a different channel to communicate immediacy behaviors electronically (Schutt, Allen, \& Laumakis, 2009). Some ways they can do this is by using emotion symbols such as a smiling face, posting a picture of the instructor on the class website, addressing emails specifically to each student using the student's name, referring to the class as 'we' or 'our' in email messages, and increased contact with students through email with students to name a few. These immediacy behaviors used through technology may build rapport with students by displaying additional forms of immediacy behaviors beyond what students are likely to expect. Instructors at small liberal arts universities displaying the usual immediacy behaviors identified by previous research is inadequate according to the results of this study to motivate students to learn. Additional forms of immediacy behaviors are needed at small liberal arts universities to better motivate their students.

\section{Future Research}

The findings from this study serve as a springboard for future research to investigate institutional type with regard to the relationships between instructors' immediacy behaviors and students' motivation to learn. Identifying additional instructor immediacy behaviors at different institutions can make major progress for instructors, administrators, and educational researchers.

\section{References}

Allen, M., Witt, P., \& Wheeless, L. (2006). The role of teacher immediacy as a motivational factor in student learning: Using a meta-analysis to test a causal model. Communication Education, 55, 21-31.

Anderman, L. (2004). Student motivation across subject-area domains. Journal of Educational Research, 97, 283-285. 
Furlich

Andersen, J. (1979). Teacher immediacy as a predictor of teacher effectiveness. In D. Nimmo (Ed.) Communication Yearbook, 3, (pp. 543-559). New Brunswick, NJ: Transaction Books.

Carnegie Foundation for the Advancement of Teaching (2010). The Carnegie Classification of Institutions of Higher Education. Retrieved November 13, 2010 at http://www.classifications.carnegiefoundation.org/

Christensen, L. \& Menzel, K. (1998). The linear relationship between student reports of teacher immediacy behaviors and perceptions of state motivation, and of cognitive, affective, and behavioral learning. Communication Education, 47, 82-90.

Christophel, D. (1990). The relationship among teacher immediacy behaviors, student motivation, and learning. Communication Education, 39, 323-340.

Christophel, D. \& Gorham, J. (1995). A test-retest analysis of student motivation, teacher immediacy, and perceived sources of motivation and demotivation in college classes. Communication Education, 44, 292-306.

Comadena, M., Hunt, S., \& Simonds, C. (2007). The effects of teacher clarity, nonverbal immediacy, and caring on student motivation, affective and cognitive learning. Communication Research Reports, 24, 241-248.

Dickson, R. (1999). The changing role of community college faculty: Implications in the literature. Community College Review, 26 (4), 23-38.

Dobransky, N., \& Frymier, A. (2004). Developing teacher-student relationships through out of class communication. Communication Quarterly, 52, 211-223.

Donelan, G. (2004). The establishment of 'teaching' universities: Perspectives from a university college. Perspective, 8, 68-73.

Elliot, J., \& Knight, J. (2005). Student motivation: The bottom line. The Agricultural Education Magazine, 77(4), 8-10.

Ellis, K. (2004). The impact of perceived teacher confirmation on receiver apprehension, motivation, and learning. Communication Education, 53, 1-20.

Fang-Yi, F., \& Wang, Y. (2010). Student silent messages: Can teacher verbal and nonverbal immediacy moderate student use of text messaging in class. Communication Education, 59, 475496.

Frymier, A. (1994). A model of immediacy in the classroom. Communication Quarterly, 42, 133144.

Frymier, A., \& Houser, M. (2000). The teacher-student relationship as an interpersonal relationship. Communication Education, 49, 207-219. 
Glynn, S., Aultman, L., \& Owens, A. (2005). Motivation to learn in general education programs. The Journal of General Education, 54, 150-170.

Gorham, J. (1988). The relationship between verbal teacher immediacy behaviors and student learning. Communication Education, 37, 40-53.

Gorham, J. \& Zakahi, W. (1990). A comparison of teacher and student perceptions of immediacy and learning: Monitoring process and product. Communication Education, 39, 354-368.

Harrison, R. (2011). Instructor transformational leadership and student outcomes. Emerging Leadership Journeys, 4, 91-119.

Houser, M. (2005). Teacher behavior, student interest and affective learning: Putting theory into practice. Communication Quarterly, 53, 71-90.

Jaasma, M. \& Koper, R. (1999). The relationship of student-faculty out-of-class communication to instructor immediacy and trust and to student motivation. Communication Education, 48, 4147.

Johnson, D. (2013). Student in-class texting behavior: Associations with instructor clarity and classroom relationships. Communication Research Reports, 30, 57-62.

Lapka, C. (2012). Getting engaged. Illinois Music Educator, 72, 72-73.

Lebedina-Manzoni, M. (2004). To what students attribute their academic success and unsuccess. Education, 124, 699-708.

Mayhew, M. (2012). A multilevel examination of the influence of institutional type on the moral reasoning development of first-year students. The Journal of Higher Education, 83, 367-388.

Mehrabian, A. (1971). Silent Messages. Belmont, CA: Wadsworth.

Modern Language Association Committee on Community Colleges (2006). A community college teaching career. Retrieved October 11, 2006 at http://www.mla.org/commcollege teachcar

Ovington, J., Diamantes, T., Roby, D., \& Ryan, C. (2003). An analysis of prevailing myths regarding tenure and promotion. Education, 123, 635-637.

Paas, F., Tuovinen, J., Merrienboer, J, \& Darabi, A. (2005). A motivational perspective on the relation between mental effort and performance: Optimizing learner involvement in instruction. Educational Technology Research and Development, 53 (3), 25-34.

Pascarella, E., Wang, J., Trolian, T., and Blaich, C. (2013). How the instructional and learning environments of liberal arts colleges enhance cognitive development. Higher Education, 66, 569583. 
Pogue, L., \& Ahyun, K. (2007). The effect of teacher nonverbal immediacy and credibility on student motivation and affective learning. Communication Education, 55, 331-344.

Proulx, T., \& Heine, S. H. (2008). The case of the transmogrifying experimenter: Affirmation of a moral schema following implicit change detection. Psychological Science, 19, 12941300.

Richmond, V., Gorham, J. \& McCroskey, J. (1987). The relationship between selected immediacy behaviors and cognitive learning. In M. McLaughlin (ED.), Communication Yearbook, 10, (pp. 574-590). Beverly Hills: Sage.

Rubin, R., Palmgreen, P., \& Sypher, H. (1994). Communication research measures: A sourcebook. New York: The Guilford Press.

Schutt, M., Allen, B., \& Laumakis, M. (2009). The effects of instructor immediacy behaviors in online learning environments. The Quarterly Review of Distance Education, 10, 135-148.

Seifert, T. (2004). Understanding student motivation. Educational Research, 46, 137-149.

Sidelinger, R. (2010). College student involvement: An examination of student characteristics and perceived instructor communication behaviors in the classroom. Communication Education, 61, 87-103.

Sorcinelli, M. (2002). New conceptions of scholarship for a new generation of faculty members. New Directions for Teaching, 90, 41-48.

Tabachnick, B., \& Fidell, L. (2001). Using multivariate statistics ( $4^{\text {th }}$ ed.). Needham Heights, MA. Allyn \& Bacon.

U.S. Department of Education (2011). National Center for Education Statistics, 2011

National Study of Postsecondary faculty. Retrieved September 21, 2011 at

http://www.nces.ed.gov/

U.S. News and World Reports (2015). U.S. News and World Reports Education Rankings and Advice. Retrieved September 28, 2015 at

http://colleges.usnews.rankingsandreviews.com/best-colleges

Velez, J., \& Cano, J. (2008). The relationship between teacher immediacy and student motivation. Journal of Agricultural Education, 49 (3), 76-86.

Wiesman, J. (2012). Student motivation and the alignment of teacher beliefs. Clearing House, 85, 102-108.

Witt, P., \& Kerssen-Griep, J. (2011). Instructional feedback I: The interaction of facework and immediacy on students' perceptions of instructor credibility. Communication Education, 60, 7594. 
Furlich

Witt, P., Wheeless, L., \& Allen, M. (2004). A meta-analytical review of the relationship between teacher immediacy and student learning. Communication Monographs, 71, 184-207.

Zhang, Q, Oetzel, J., Gao, Z., Wilcox, R., \& Takai, J. (2007). A further test of immediacy-learning models: A cross-cultural investigation. Journal of Intercultural Communication Research, 36, 113. 